\title{
Development of a Magnetic Nanostructure for Co-delivery of Metformin and Silibinin on Growth of Lung Cancer Cells: Possible Action Through Leptin Gene and its Receptor Regulation
}

\author{
Elnaz Salamni Javan', Fatemeh Lotfi', Davoud Jafari-Gharabaghlou', Hanieh \\ Mousazadeh $^{1}$, Mehdi Dadashpour ${ }^{2,3 *}$, Nosratollah Zarghami ${ }^{1,4 *}$
}

\begin{abstract}
Objective: Chemotherapeutic combinational approaches would be more efficient in decreasing toxicity of drug, preventing tumor progression in relation to either drug alone. Hence, the aim of this study is to constract magnetic PLGA/PEG nanoparticles (NPs) co-loaded with Metformin (Met) and Silibinin (Sil) to investigate their cytotoxicity as well as their impact on mRNA expression levels of leptin and leptin receptor genes in A549 lung cancer cells. Materials and Methods: The synthesized NPs were characterized by FTIR, FE-SEM, and VSM and then, MTT assay was utilized to assess and compare the cytotoxicity of various concentrations of the chemotheruptic molecules in pure and nanoformulated forms as well as in alone and combination state after $48 \mathrm{~h}$ exposure time. Moreover, the mRNA levels of leptin and its receptor genes expression were studied by quantitative real-time PCR. By co-encapsulation of Met and Sil into PLGA/PEG/ $\mathrm{Fe}_{3} \mathrm{O}_{4}$, cytotoxic efficiency of the compounds considerably augmented for all concentrations. Results: Cytotoxicity assay displayed that combination of Met and Sil had a synergistic concentration-dependent effect on A549 lung cancer cells. Moreover, qPCR data revealed that the expression levels of the leptin and leptin receptor was considerably reduced with increasing concentrations of drug-encapsulated magnetic NPs, especially Met/Sil-encapsulated PLGA/PEG/ $\mathrm{Fe}_{3} \mathrm{O}_{4}$ NPs. Conclusion: Present preliminary study shows that co-incorporating Met, $\mathrm{Sil}_{,} \mathrm{Fe}_{3} \mathrm{O}_{4}$ into PLGA/PEG NPs might provide a more promising and safe treatment strategy for lung cancer.
\end{abstract}

Keywords: Silibinin- Metformin- Magnetic PLGA/PEG nanoparticles- Lung cancer- Leptin

Asian Pac J Cancer Prev, 23 (2), 519-527

\section{Introduction}

Cancer is an uncontrolled development of cells with the potential to attack, or spread to, other tissues and organs of the body (Jeddi et al., 2019; Nikmanesh et al., 2020; Abbasi et al., 2021). Lung cancer is one of the most common and dangerous kinds of cancer throughout the world (Sheervalilou et al., 2016; Mellatyar et al., 2018) . Lung cancer as a malignant tumor characterized through unchecked cell growth in the lung tissue (Adlravan et al., 2021). Different kinds of non-small cell lung cancer, are the mainly common types of lung cancer (Samadzadeh et al., 2021). Three standard therapeutic approaches of lung treatment options including surgery, chemotherapy and, radiation therapy usually are used according to the type and stage of cancer (Farajzadeh et al., 2018). But the use of some these treatment strategies are limited due to the lack of considerable progress on survival rate and the metastatic tumors(Maasomi et al., 2017). Moreover, among the therapeutic strategies, particularly chemotherapy has some undesirable side effects such as nausea, fatigue, neutropenia, anemia and hair loss (Abotaleb et al., 2018). Hence developing novel treatment methods with minimal side effects is crucial. Nowadays, various natural compounds or phytochemicals have been isolated, and their potential anti-tumor efficiency have been assessed (Farajzadeh et al., 2018; Jafari-Gharabaghlou et al., 2018). Among them, some phytochemicals such as Silibinin (Sil) and Metformin (Met) showed promising chemopreventive potential against different malignancies in both in vitro and in vivo studies (Chatran et al., 2018; Amirsaadat et al., 2021).

Sil, a flavonoid derived from Silybum marianum, has been thoroughly assessed for preventing the

${ }^{1}$ Department of Clinical Biochemistry and Laboratory Medicine, Faculty of Medicine, Tabriz University of Medical Science, Tabriz, Iran. ${ }^{2}$ Department of Medical Biotechnology, Faculty of Medicine, Semnan University of Medical Sciences, Semnan, Iran. ${ }^{3}$ Biotechnology Research Center, Semnan University of Medical Sciences, Semnan, Iran. ${ }^{4}$ Department of Medical Biochemistry, Istanbul Aydin University, Istanbul, Turkey.*For Correspondence: dadashpourm@semums.ac.ir, zarghami@tbzmed.ac.ir 
growth of different malignancies via wide in vitro and in vivo examinations. Sil alone and in combination with other chemotherapeutic molecules exhibited effective anticancer activity via inhibition of cancer cell proliferation, angiogenesis and epigenetic-associated processes (Pourgholi et al., 2021). Met is a standard clinical drug to choose for treating polycystic ovary syndrome and type 2 diabetes mellitus (Mogheri et al., 2021). In vivo and in vitro researches have exposed that Met has a direct anticancer effect through decreasing the proliferation and triggering the apoptosis of cancer cells (Zakikhani et al., 2006). Recent advances for efficient treatment of cancer are based on an combining of various chemotherapeutic molecules with different mechanism of actions (Dai et al., 2017). Besides, suppressing a single target does not definitely eradicate cancer cell, thus applying a combination of molecular-targeted drugs have been reported (Nagaraj and Datta, 2010). Combination therapy, mainly in the elimination of obstacles such as tumor resistance and low drug effectiveness can be effective to achieve better clinical outcomes to the single drug (Cukierman and Khan, 2010). Leptin, a product of $\mathrm{Ob}$ gene secreted by adipose tissue that regulates the balance between orexigenic and anorexigenic by binding to hypothalamic receptors and controls appetite, energy expenditure, and body mass composition (Ahima and Flier, 2000). The role of leptin in lung cancer is not clear (Dutta et al., 2012).

Primary findings proved the presence of ObRl in squamous cell carcinoma (SCC) of the lung and human lung tissue in which leptin lead to an increase in cell growth through the ERK1/2 pathway (Tsuchiya et al., 1999). Besides, it was found that ERK $1 / 2$ pathway is induced in A549 cells via leptin (Xu et al., 2018)

Numerous studies have showed that polymeric nanoparticles (NPs) significantly contribute for improving the co-delivery efficiency of chemotherapeutic agents due to their easy penetration into cell membranes, decreasing the off-target effects, and lysosomal escaping following endocytosis (Hashemi et al., 2021; Mousazadeh et al., 2021). As a biomaterial approved by FDA, poly lactic-coglycolic acid (PLGA) is known for biocompatibility and ability to biodegrade due to its long-term clinical trials (Firouzi-Amandi et al., 2018; Javan et al., 2019). The structure and the solubility of drug molecules-controlled drug release rate. Moreover, the hydrophilic block of polyethylene glycol (PEG) has showed great potential in decreasing the protein adsorption, opsonization and subsequent clearance as well as increasing blood circulation. there have been significant achievements in the application of NPs in disease diagnostic and highly efficient targeted therapy, it is vital that the systems are biocompatible and capable of being multifunctional for recognition of specific target tumor sites (Serati-Nouri et al., 2021). In the current work, we aimed to evaluate the cytotoxicity efficiency of Met and Sil co-encapsulated into PLGA/PEG/ $/ \mathrm{Fe}_{3} \mathrm{O}_{4}$ NPs against A549 human lung cancer cells. Also, the impact of the co-loaded magnetic PLGA/PEG NPs on the expression of leptin and leptin receptor genes as a possible molecular mechanism of their anticancer activity were investigated.

\section{Materials and Methods}

\section{Materials}

The A549 lung cell line (lung adenocarcinoma cells) obtained from National Center for Genetic and Biological Resources of Iran. $\mathrm{FeCl} 2.4 \mathrm{H}_{2} \mathrm{O}, \mathrm{FeCl}_{3} \cdot 6 \mathrm{H}_{2} \mathrm{O}$ ) and Ammonia solution (25wt \%) were obtained from Fluka (Buchs, Switzerland). Silibinin, Metformin, Roswell Park Memorial Institute (RPMI) 1640, Fetal Bovine Serum (FBS), MTT powder, Streptomycin/penicillin, dimethyl sulfoxide (DMSO) and dichloromethane (DCM) were gained from from Santa Cruz Biotechnology (Santa Cruz, CA, USA).

\section{Preparation of PLGA/PEG/Fe ${ }_{3} \mathrm{O}_{4} \mathrm{NPS}$}

The ring-opening polymerization method was utilized to synthesize of PLGA-PEG copolymers. Pre-determined quantity of glycolide, D, L-lactide, and PEG4000 were melted at $120^{\circ} \mathrm{C}$ under nitrogen. Next, Sn(Oct)2 (0.01 $\mathrm{mmoL}$ ) was added and the polymerization reaction was continued for $2 \mathrm{~h}$ (Yang et al., 2006). Next, the generated product was dissolved in dichloromethane, and finally, the precipitation process followed in cold diethyl ether solvent

\section{Preparation of drug-loaded NPS}

For encapsulation of Met/Sil in PLGA/PEG/Fe $\mathrm{O}_{4}$ NPs, double emulsion method was utilized. Firstly, PLGA/ PEG (250 mg) was dissolved in in dichloromethane (DCM, $5 \mathrm{ml})$. PVA (20 ml, 0.5\% w/v) including Met and Sil (20 mg) was added to the organic phase and emulsified with sonicator probe with the power of $10 \mathrm{~W}$ for 45 seconds to produce w/o/w emulsion. Then, to evaporate the organic phase, the obtained emulsion was stirred in room temperature and the remaining solution was centrifuged for 40 minutes at 15,000 rpm and freeze-dried for the elimination of all of the residual solvents

\section{NPS characterization}

The field emission scanning electron microscopy (FE-SEM) (MIRA3 TESCAN, Czech) was applied to determine NPs morphology The Dynamic Light Scattering (DLS) was utilized to analyze the NPs average size. The structure confirmation of PLGA/PEG/Fe $\mathrm{O}_{4}$ NPs was investigated via Fourier transform infrared (FTIR) spectroscopy (BRUKER series). The Vibrating Sample Magnetometer (VSM) is based on vibrating a sample magnetometer (VSM; Lakeshore Cryotronics, Westerville, $\mathrm{OH}$ ) magnetization curves were measured at room temperature.

\section{In vitro release study}

The behavior discharge of agents from magnetic NPs was studied at $\mathrm{pH} 7.4 .3 \mathrm{mg}$ of Met/Sil encapsulated magnetic NPs was scattered in $20 \mathrm{~mL}$ PBS and added in a dialysis tubing, and then incubated at $37^{\circ} \mathrm{C}$ with stirring at $70 \mathrm{rpm}$. Predetermined time points, $2 \mathrm{~mL}$ of fresh PBS was added to keep the constant volume to each sample. The released of Met and Sil measured using Lambda 950 Visible-UV spectrophotometer at 237 and $288 \mathrm{~nm}$ and the Met and Sil released concentration was calculated according to the standard curve. 
Drug encapsulation efficiency and drug loading

To determine the efficiency of drug encapsulation, after the synthesis of drug-loaded NPs, the supernatant of the tube was isolated and the quantity of non-entrapped drugs assessed via was defined via Visible-UV spectrophotometer at 237 and $288 \mathrm{~nm}$ wavelength for Sil and Met respectively. In the following, the percent of entrapped drug (Encapsulation Efficiency; EE) and drug loading (DL) were computed by employing the following formulas:

$$
\begin{aligned}
& \mathrm{DL}(\%)=\frac{\text { Amount of drug entrapped }}{\text { Amount of NP}} \times 100 \\
& \mathrm{EE}(\%)=\frac{\text { Amount o } f \text { drug entrapped }}{\text { mount of drug added }} \times 100
\end{aligned}
$$

\section{Cytotoxicity Assay}

The A549 lung cell line were cultured in RPMI-1640 media plus $10 \%$ FBS and 1\% streptomycin/penicillin and incubated at $5 \%$ humidity in sterile flasks. MTT assay was utilized to study the viability of cells. Briefly, A549 lung cancer cells (7,000/well) were seeded in 96-well plates and incubated to help cell attachment. After 24 h, cells were exposed to Met, Sil, Met/Sil, Met-loaded PLGA/PEG/ $\mathrm{Fe}_{3} \mathrm{O}_{4}$ NPs, Sil-loaded PLGA/PEG/ Fe $\mathrm{O}_{4}$ NPs, Met/Sil-loaded PLGA/PEG/ $\mathrm{Fe}_{3} \mathrm{O}_{4} \mathrm{NPs}$ for $48 \mathrm{~h}$. Next, MTT solution $(0.5 \mathrm{mg} / \mathrm{mL}, 200 \mu \mathrm{L})$ was added to all wells and incubated for 4 hours. After incubation for $4 \mathrm{~h}$ at $37^{\circ} \mathrm{C}$, the medium was evacuated and DMSO (100 $\mu \mathrm{L}$ ) was included in each well. Finally, rate of absorbance was assessed through a microplate reader (Star fax 3200 (Awareness Technology Inc.) at $570 \mathrm{~nm}$.The data on mean \pm SD $(n=3)$ were displayed in each test.

\section{Real-time PCR assay}

A549 cells were plated into 6-well plate and treated with free and nanofurmulated drugs for $48 \mathrm{~h}$ and and total RNA was extracted using RNeasy mini kit (Qiagen, USA) according to the manufacturer's procedure. RNA quality and quantity determined by a NanoDrop
(ThermoScientific, USA). For the cDNA synthesis, an appropriate proportion of RNA was taken from each sample and reverse transcribed through RevertAid First strand cDNA synthesis Kit (Fermentas, St Leon-Rot, Germany). Real-Time PCR system was followed using Syber Green Master Mix (BioMolecular Systems, Australia) for the target genes applying the selected primers. Relative expression of each gene was normalized via housekeeping gene (GAPDH) and quantified utilizing $2^{-\Delta \Delta C t}$ method. All the experiments were done in triplicate.

After treating A549 cells with different concentrations of the NPs for $48 \mathrm{~h}$. Total RNA was extracted using TRIzol reagent (Invitrogen, USA). According to producer's instructions, Nanodrop was verified the purity and quantity of total RNA. RevertAid ${ }^{\mathrm{TM}}$ First Strand cDNA synthesis kit (Thermo Fisher Scientific, MA, USA) was used for synthesizing cDNA from $1 \mu \mathrm{g}$ RNA. Finally, the $2^{-\Delta \Delta C t}$ method was applied to determine the relative quantification and the gained data were normalized to the levels of the $\beta$-actin gene as a housekeeping control.

\section{Statistical analysis}

Statistical significance was done using GraphPad Prism $^{\circledR}$ version 8.0 software, USA.The results were evaluated using one-way ANOVA Analysis of Variance. All the samples were analyzed in triplicates and the results provide as mean \pm standard deviation (SD) for $n=3$. The level of significance was considered by $\mathrm{p}$-value. Statistically, $\mathrm{P}$ value $<0.05$ was considered significant.

\section{Results}

\section{Characterization of nanoparticles}

Spherical morphology homogeneously distributed without any significant aggregation in the synthesized NPs was confirmed via FE-SEM analysis. The micrographs of Met/Sil-encapsulated PLGA/PEG/ $\mathrm{Fe}_{3} \mathrm{O}_{4}$ NPs are shown in Figure 1. The sizes of Met/Sil-loaded PLGA/PEG/ $\mathrm{Fe}_{3} \mathrm{O}_{4}$ NPs were about $160-220 \mathrm{~nm}$. The dispersion of the NPs was greatly improved. DLS data analysis showed a
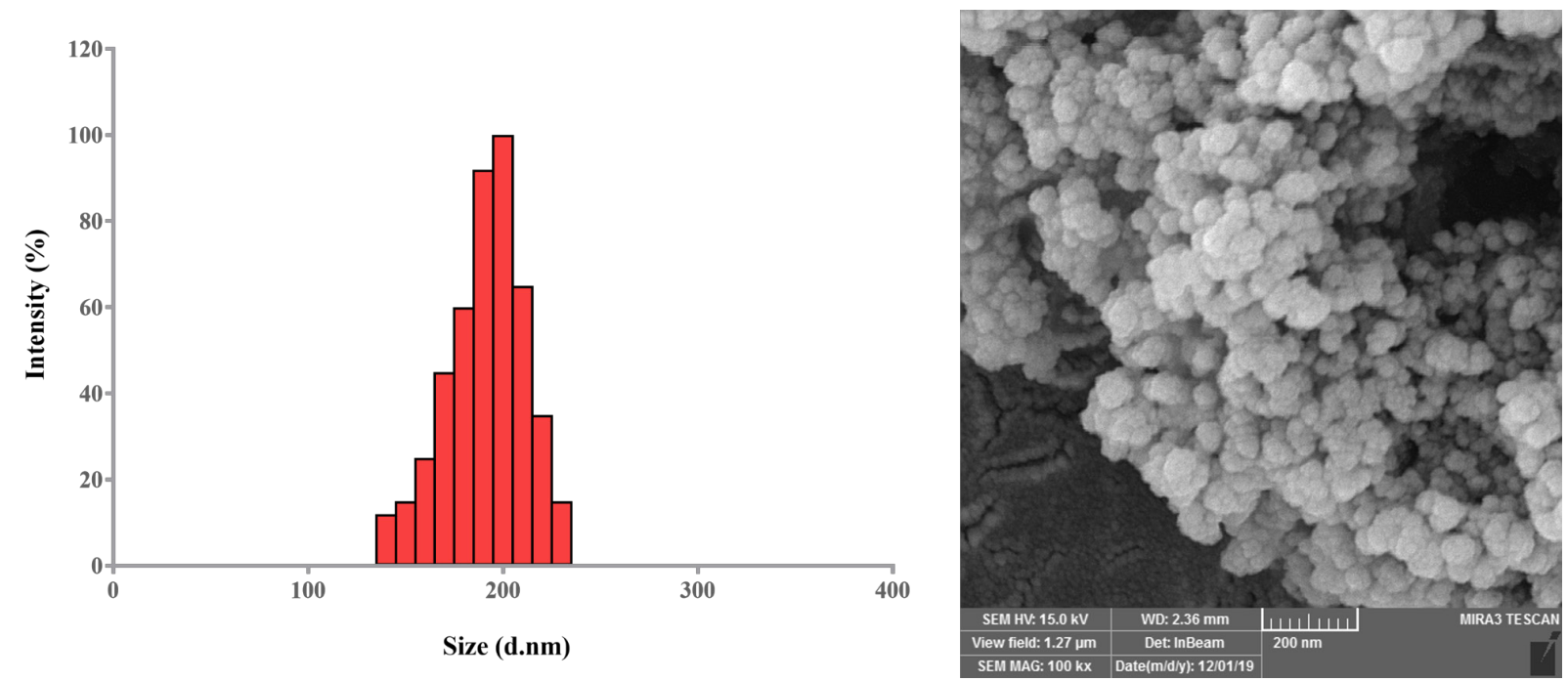

Figure 1. A) DLS histogram showing the size distribution of Met/Sil-loaded PLGA/PEG/ Fe $\mathrm{O}_{4} \mathrm{NPs}$. The average size ranged from 160 to $220 \mathrm{~nm}$. B) Field emission scanning electron microscopy (FE-SEM) image of surface morphology of Met/Sil-loaded PLGA/PEG/ $\mathrm{Fe}_{3} \mathrm{O}_{4}$. 


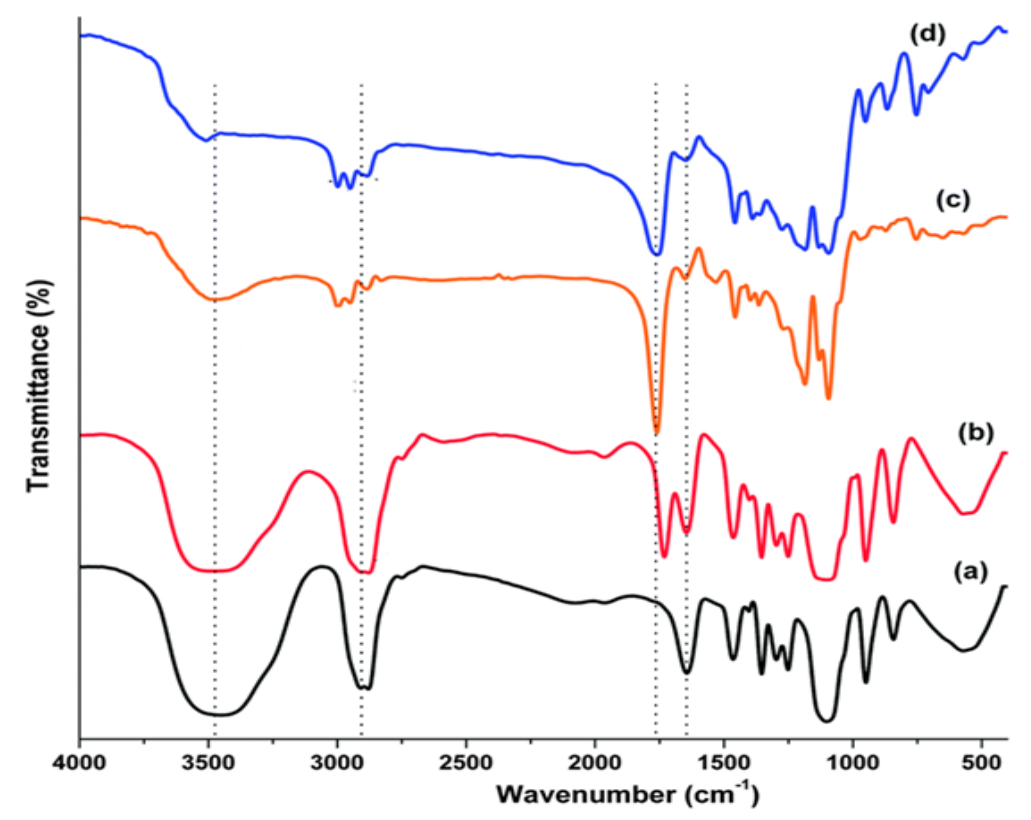

Figure 2. FTIR Spectra of (A) PLGA/PEG/ Fe $\mathrm{O}_{4}$ NPs, (B) Sil-loaded PLGA/PEG/ Fe3O4 NPs, (C) Met-loaded PLGA/PEG/Fe Fe3O4 NPs, and (D) Met/Sil-loaded PLGA/PEG/ $\mathrm{Fe}_{3} \mathrm{O}_{4}$ NPs.

uniform distribution of particles with an average size of $140 \mathrm{~nm}$, a polydispersity index of 0.157 and zeta potential of $-23.4 \pm 3.6 \mathrm{mV}$ for PLGA/PEG/ $\mathrm{Fe}_{3} \mathrm{O}_{4} \mathrm{NPs}$. Moreover, it was found that PLGA/PEG/ $\mathrm{Fe}_{3} \mathrm{O}_{4}$ NPs loaded with Met and Sil had an average size of 180 and $190 \mathrm{~nm}$, respectively.

Chemical structures of the synthesized NPs were studied by FTIR spectroscopy (Figure 2). The stretching vibration mode of $\mathrm{Fe}-\mathrm{O}$ bonds in $\mathrm{Fe}_{3} \mathrm{O}_{4}$ assigned to the absorption peaks at $720 \mathrm{~cm}^{-1}$. The absorption band at $3509.9 \mathrm{~cm}^{-1}$ belonged to hydroxyl groups at the PEG end in the copolymer from which PEG homopolymer has been eliminated. The bands at $2885 \mathrm{~cm}-1$ due to stretch vibration $\mathrm{C}-\mathrm{H}$, and a strong band at $1635 \mathrm{~cm}-1$ is due
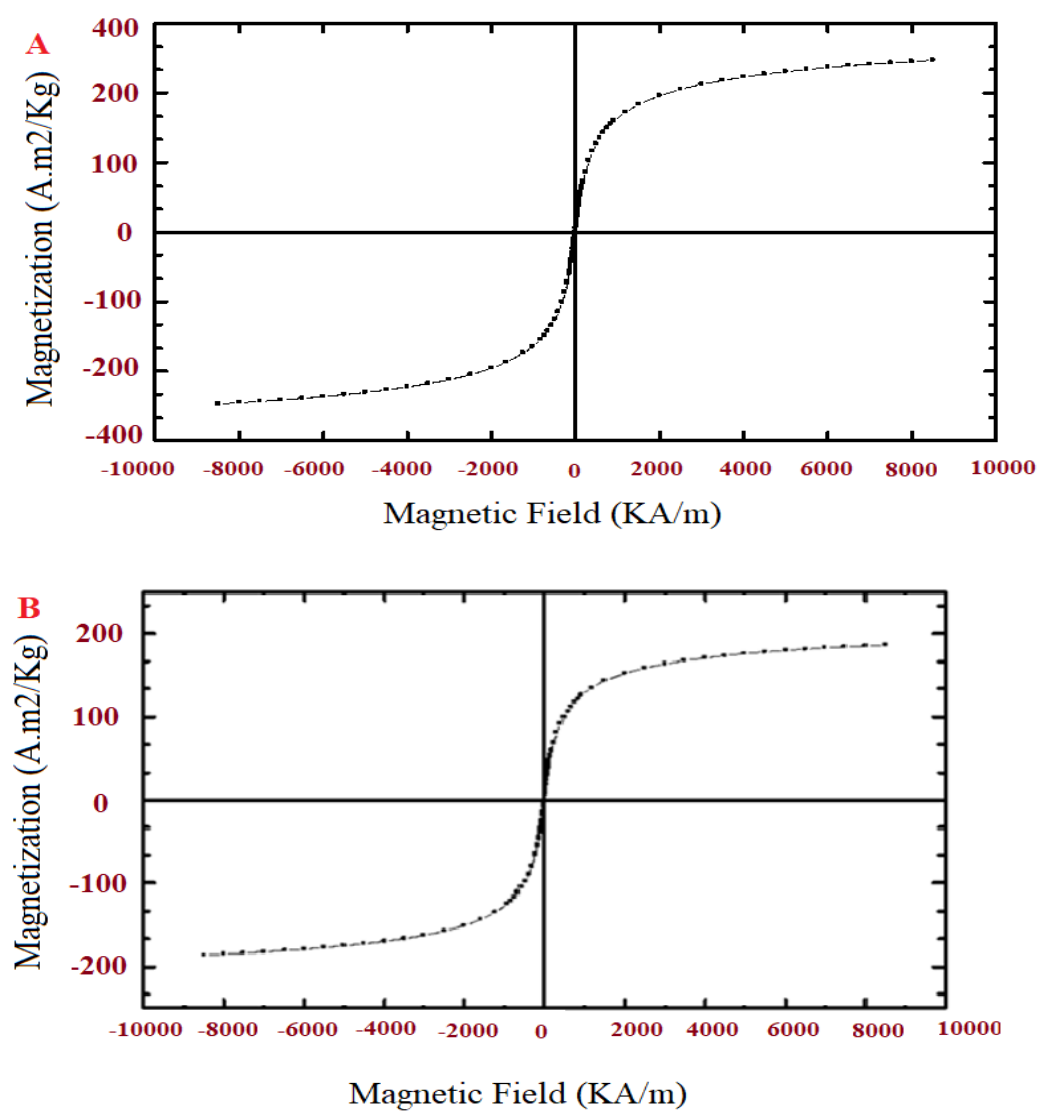

Figure 3. Magnetic Hysteresis Curve of Pure $\mathrm{Fe}_{3} \mathrm{O}_{4}$ NPs (A), and Met/Sil-loaded PLGA/PEG/F Fe $\mathrm{O}_{4}$ NPs (B). 


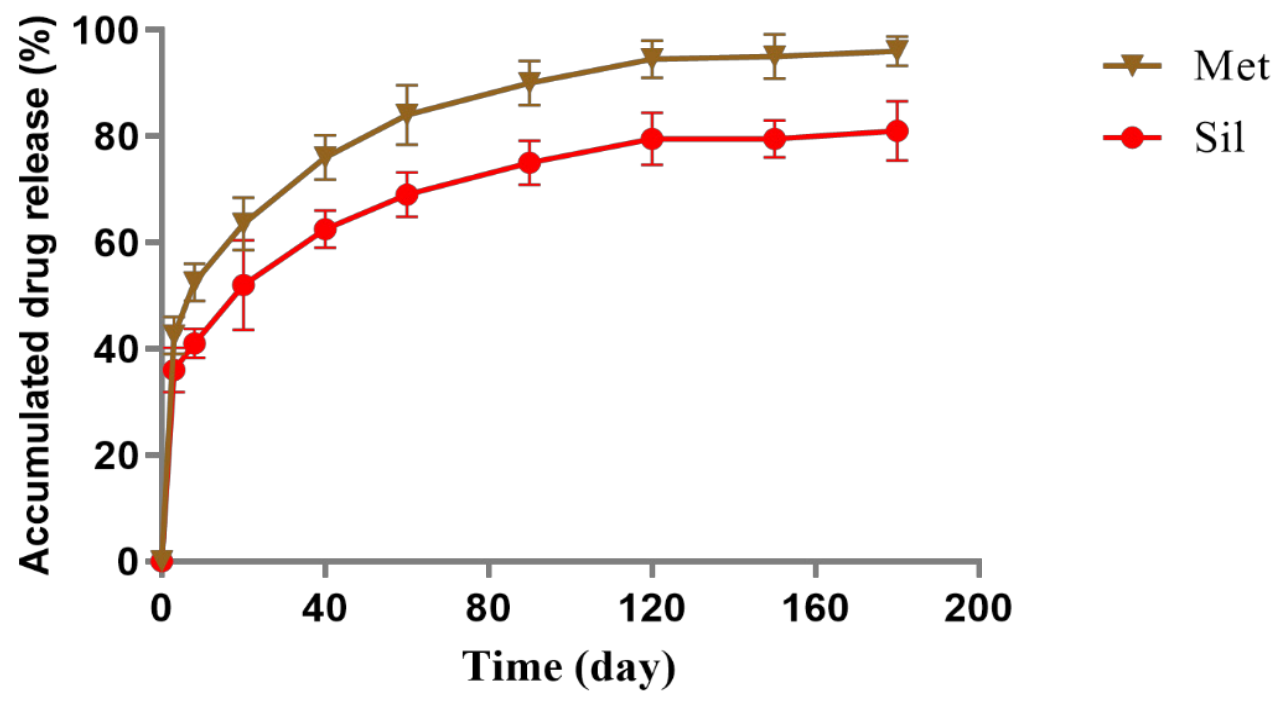

Figure 4. Dischage Profile of Sil and Met from Met/Sil-loaded PLGA/PEG/ $\mathrm{Fe}_{3} \mathrm{O}_{4} \mathrm{NPs}$ at $\mathrm{pH}$ 7.4. The data are presented as mean $\pm \mathrm{SD}(\mathrm{n}=3)$.

to $\mathrm{C}=\mathrm{O}$ stretch. Absorption at $1090.6 \mathrm{~cm}-1$ belonged to $\mathrm{C}-\mathrm{O}$ stretch. These absorption bands indicate that the encapsulation of drugs in magnetic nanoparticles was successful.

To measure the magnetic futures of the pure $\mathrm{Fe}_{3} \mathrm{O}_{4}$ NPs and Sil/Met encapsulated in PLGA/PEG/F $\mathrm{F}_{3} \mathrm{NPs}^{3}$, a vibrating sample magnetometer (VSM) technique was used at room temperature. According to the hysteresis curve in Figure $3 \mathrm{~A}$, the saturation value of magnetization of the pure $\mathrm{Fe}_{3} \mathrm{O}_{4} \mathrm{NPs}$ was found to be $56 \mathrm{emu} / \mathrm{g}$. Also, in Figure $3 \mathrm{~B}$, the saturation value of magnetization of the Sil/Met-encapsulated PLGA/PEG/ $\mathrm{Fe}_{3} \mathrm{O}_{4}$ NPs is lower than the saturation value of magnetization of the pure $\mathrm{Fe}_{3} \mathrm{O}_{4}$ NPs presented $(9 \mathrm{emu} / \mathrm{g})$. This difference indicates that the co-encapsulation of $\mathrm{Fe}_{3} \mathrm{O}_{4}$, Sil and Met in PLGA/ PEG copolymers was successful. After the elimination of the magnetic field, no magnetic activity was observed in the magnetic polymer NPs. This property of magnetic NPs is very important in its applications in biomedical and bioengineering fields.

\section{Drug release profile}

In this study, the release rate of Met and silibinin from Met/Sil-loaded PLGA/PEG/ $\mathrm{Fe}_{3} \mathrm{O}_{4}$ NPs were investigated at pH 7.4 (Figure 4) Up to 180 hours, the release rate of Sil and MET from the the nanoparticulate drug release systems were about $65 \%$ and $85 \%$ respectively. Both theraputic molecules have been shown to exhibit an intial

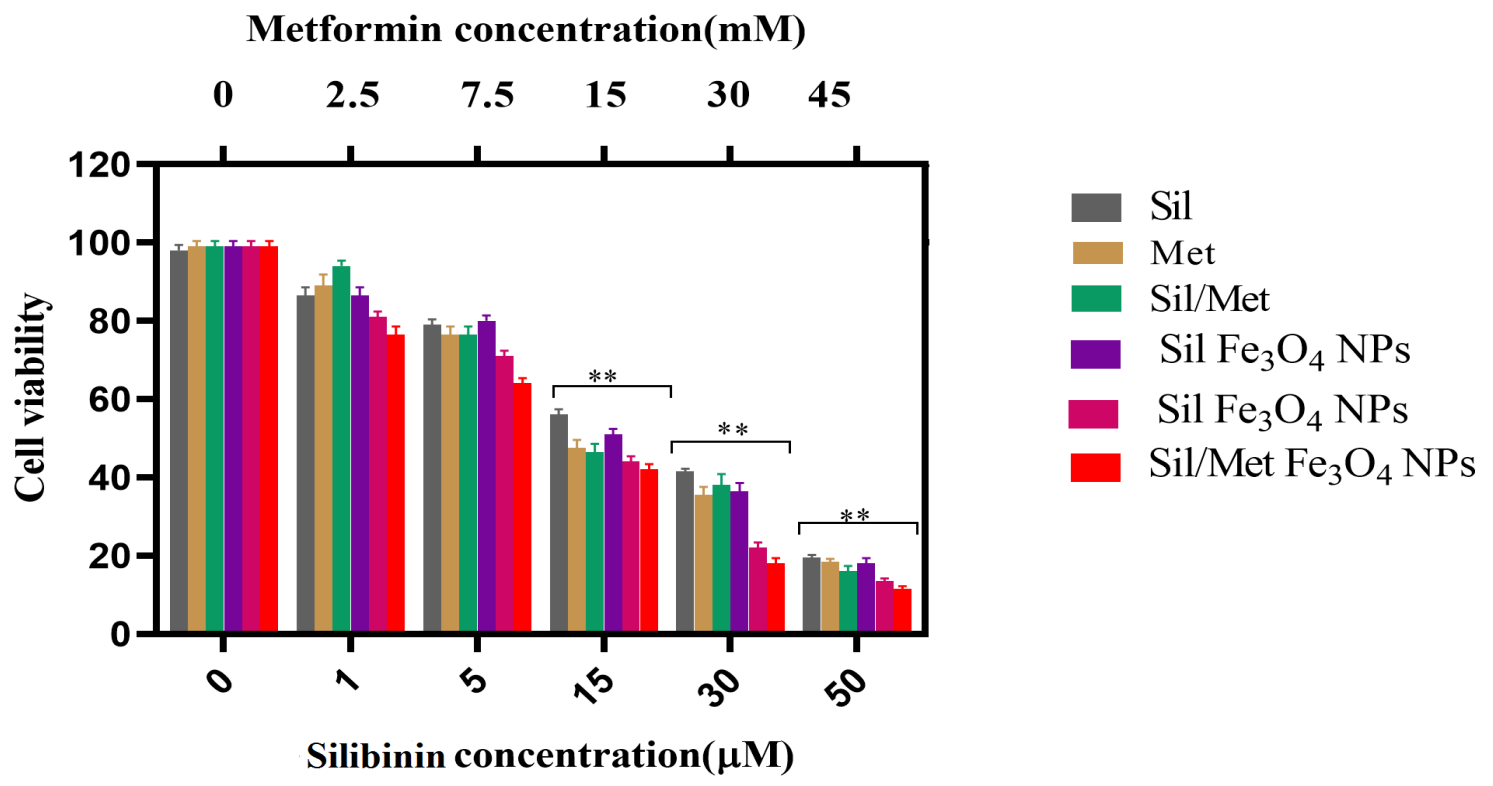

Figure 5. (A) in vitro cytotoxicity of pure Met, pure Sil, pure Met/Sil, Met-loaded PLGA/PEG/F $\mathrm{Fe}_{3} \mathrm{O}_{4} \mathrm{NPs}$, Sil-loaded PLGA/PEG/ $\mathrm{Fe}_{3} \mathrm{O}_{4}$ NPs, and Met/Sil-loaded PLGA/PEG/ $\mathrm{Fe}_{3} \mathrm{O}_{4}$ NPs against A549 cells incubated for 48 $h$. The data are presented as mean $\pm \operatorname{SD}(n=3)$. 

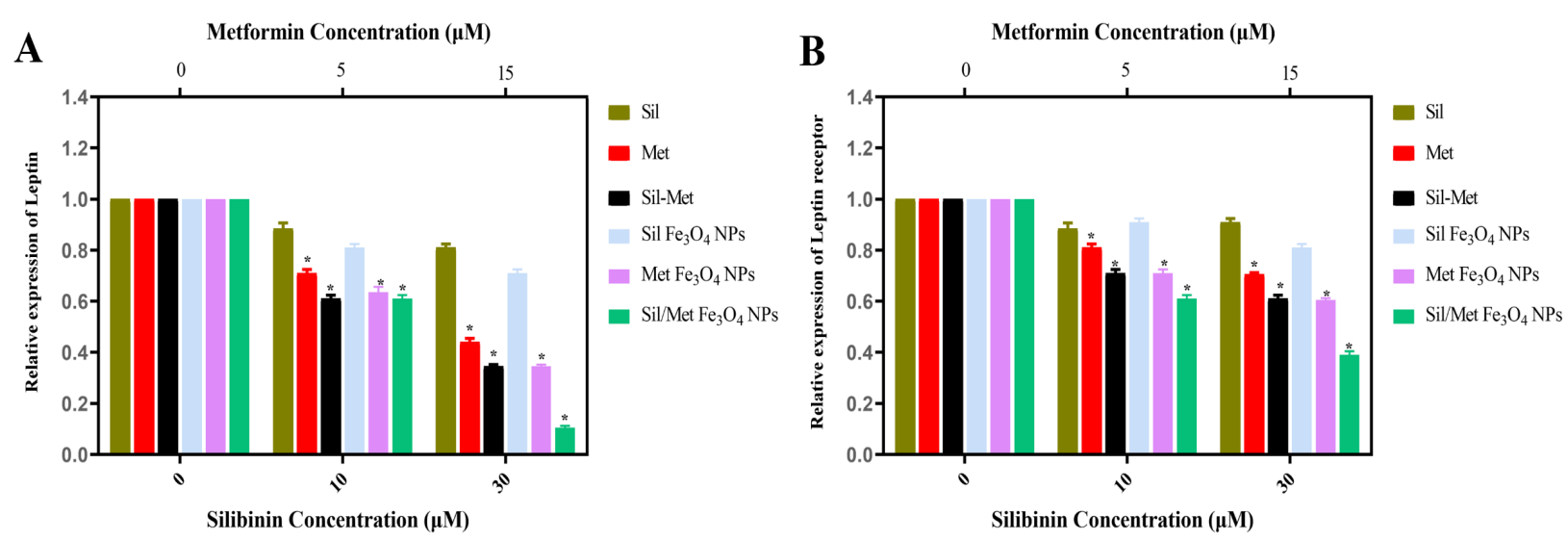

Figure 6. Expression Levels of (A) leptin and (B) leptin receptor in A549 lung cancer cells by treatment with different concentrations of pure Met, pure Sil, pure Met/Sil, Met-loaded PLGA/PEG/ $\mathrm{Fe}_{3} \mathrm{O}_{4} \mathrm{NPs}$, Sil-loaded PLGA/PEG/ $\mathrm{Fe}_{3} \mathrm{O}_{4}$ NPs, and Met/Sil-loaded PLGA/PEG/ $\mathrm{Fe}_{3} \mathrm{O}_{4}$ NPs. ${ }^{*} \mathrm{p}<0.05$ vs. other groups was considered significant. The data are presented as mean $\pm \mathrm{SD}(\mathrm{n}=3)$.

burst release for the first 8 hours followed with slow rlease rate. Furthermore, the results showed that the release of hydrophic Sil molecules from the NPs were slower than hydrophilic Met molecules.

Drug loading (DL) and determination of the entrapment efficiency (EE)

Nanoencapsulation efficiency plays very essential role in delivery of drug by NPs. The nanoencapsulation efficiency of Met, Sil and Sil/Met were found to be 75.4 $\pm 2.6 \%, 83.28 \%$ and $85.39 \%$, respectively. Moreover, the capacity of drug loading of Sil and Met found to be $13.6 \pm$ $3.1 \%$ and $12.3 \pm 4.2 \%$, respectively. It seems that the high encapsulation efficacy of these natural antitumor drugs is due to their hydrophobic nature.

\section{Cell viability}

Based on the $\mathrm{IC}_{50}$ obtained from the cytotoxicity assay, data analysis showed that $\mathrm{IC}_{50} \mathrm{~s}$ of pure Met, pure Sil, pure Met/Sil, Met-loaded PLGA/PEG/ $\mathrm{Fe}_{3} \mathrm{O}_{4} \mathrm{NPs}$, Sil-loaded PLGA/PEG/ $\mathrm{Fe}_{3} \mathrm{O}_{4} \mathrm{NPs}$, and Met/Sil-loaded PLGA/PEG/ $\mathrm{Fe}_{3} \mathrm{O}_{4} \mathrm{NPs}$ on A549 lung cancer cell line is $14.31 \mathrm{mM}, 35.92 \mu \mathrm{M}, 17.63,26.37,12.03,10.51 \mu \mathrm{M}$ for $48 \mathrm{~h}$ MTT assays (Figure 5), respectively. These finding for the treatment of A549 cells, different concentrations of pure Met, pure Sil, and nanocapsulated in PLGA/PEG/ $\mathrm{Fe}_{3} \mathrm{O}_{4}$ NPs have an inhibitory effect on cancer cells at 48 hours. With increasing concentration, the toxicity of nano-encapsulated Met and Sil was higher than the toxicity of pure Met and pure Sil. The effect of the combination agent at 48 hours showed that the synergistic combinations of two agents had a higher synergistic effect compared to the individual agent as well as were able to overome toxicity and other side effects of single agent $(\mathrm{P}<0.05)$ which express an interaction between the two agents. Therefore, these results revealed that the use of this agents in the form of pure and nanocapsulated, even at the lowest dilution, have synergistic effects.

\section{Gene experssion analysis}

Real-time PCR was used to quantify leptin gene expression in A549 cell line treated with pure and magnetic nanoform of Met and Sil (Figure 6). GAPDH region normalized and calculated by the $2^{-\Delta \Delta c t}$ method to assess the level of leptin and leptin receptor gene expression changes between the control and treated A549 cells. The expression level of leptin and its receptor genes were declined by all types of treatments. It was found that nano-encapsulated forms of Met and Sil in PLGA/ PEG/ $\mathrm{Fe}_{3} \mathrm{O}_{4}$ NPs significantly decreased leptin gene expression as compared to alone and combination forms of chemotheruptic molecules. the highest decrease in leptin and its receptor gene expressions were detected on the cells treated with Met/Sil-loaded PLGA/PEG/ $\mathrm{Fe}_{3} \mathrm{O}_{4} \mathrm{NPs}$.

\section{Discussion}

To reduce deaths from lung cancer, expand new treatments or prevent them is very important. The importance of targeted drug delivery for antitumor drug and supressing side effects on normal cells is essential (Akbari et al., 2021). Combination therapy is of great interest due to the synergistic effect of the drugs (Moorthi and Kathiresan, 2013). The use of Sil as a potential compound in the treatment of various cancers have reported by many researches (Singh and Agarwal, 2006). These effects appear to be due to the ability of Sil to suppress cell proliferation, prevent cell division, increase expression of cell cycle inhibitors, increase apoptosis and suppress transcription factors (Singh and Agarwal, 2006). Some of the signaling pathways affected by Sil are MAPK and AKT (Singh and Agarwal, 2004). Met exerts its anticancer effect by activating the AMPK pathway . Met prevents cancer cell mitosis by inducing immune activation and thereby reducing growth factor signaling (Faramarzi et al., 2019). MicroRNA222 suppression induced by Met administration leads to increased levels of p27 and p57 molecules and consequently disrupts cell cycle in tumor cell . Leptin is made by adipose tissue in the human body and released into the blood(D'Marco et al., 2020) . Magnetic NPs can be used in the treatment of cancer cells through hyperthermia (Kobayashi, 2011). One of the approaches is used in the treatment of cancer is magnetic hyperthermia. This therapeutic method of hyperthermia, 
the fluid containing Magnetic NPs is injected into the cancerous tissu (Thiesen and Jordan, 2008). By creating an alternating magnetic field, these particles vibrate and generate heat, increasing the temperature of the cancerous tissue (Latorre and Rinaldi, 2009). This method will make chemotherapy work better (Salloum et al., 2008). As a result, it raises the temperature of tissue to 4 and causes the cancer cells to be completely destroyed (Johannsen et al., 2010). Research has shown that the use of magnetic NPs causes the entire cancer tissue to be affected by heat (Deatsch and Evans, 2014). Leptin reduces the production of the hypothalamic neuropeptide $\mathrm{Y}$, which is a potent stimulus of appetite (thereby reduces appetite) (Shen et al., 2009). The leptin receptor is a membrane receptor belonging to the class 1 cytokine family Leptin exerts its function through it (Bain et al., 2014). Both leptin and its receptor are involved in mitogenic factors in breast cancer (Artac and Altundag, 2012). Therefore, they can be considered as targets for the treatment of lung cancer.

As the impact of NPs size on the biopharmaceutical aspects and discharge efficiency of drug, it was evaluated by DLS and SEM observations (Mollazade et al., 2011). Also, it has been suggested that most cells are capable of passing NPs with a diameter smaller than $400 \mathrm{~nm}$ through their membranes.. In terms of charge the surface chemistry of NPs play a crucial role in influencing the stability amount of NPs emulsions and the interaction between the cell membrane and NPs (Mohandesnezhad et al., 2020). The higher zeta potential value causes natural colloidal, long term stability of NPs due to negative repulsion. Therefore, it seems that the measurement of Met and Sil loaded PLGA/PEG/ $\mathrm{Fe}_{3} \mathrm{O}_{4}$ NPs will be acceptable for achieving longevity in blood and passive targeting mechanism of cancer cells. There was a important difference between the treated and control cells in the levels of leptin and leptin receptor gene expression, both of which were declined in the treated cells in relative to the control cells (Nejati-Koshki et al., 2014). Magnetic NPs can be used in therapeutic cancer cells by hyperthermia and agents can be loaded into magnetic NPs and used in targeted cancer treatment (Sivakumar et al., 2014; Nejati et al., 2021). Previous research has shown that the combination of Magnetic NPs with Met or Sil with other drugs has potent anti-cancer effects on cancer cells (Rasouli et al., 2020). The results of the present study were also in line with the results of the above research. The combination of Met and Sil with increased suppression of leptin gene expression in a cellular model of lung cancer. In this study, cytotoxicity assay showed that Met and Sil had a lethal effect on A549 cells in a concentration-dependent manner and nano-Met/Sil significantly reduced $\mathrm{IC}_{50}$ in $48 \mathrm{~h}$. With increasing concentration, nano-encapsulated forms of Met and Sil have been shown to be more toxic than pure Met and Sil. The effect of the combination drug after 48 hours showed that the combination of the two drugs had a higher synergismic effect compared to the single drug. The results have shown that the use of these compounds were pure and nano encapsulated, even at the lowest dilution with a synergistic effect. Real-time PCR results revealed that Met and Sil, inhibited leptin and its receptor gene expression in a dose-dependent manner. In addition, Met and Sil co- loaded in PLGA/PEG/ $\mathrm{Fe}_{3} \mathrm{O}_{4}$ NPs reduced significantly the expression level of the leptin and its receptor gene.

In conclusion, in the current work, magntic PLGA/ PEG loaded with Met and Sil were developed to examine the impact of Met and Sil on growth and proliferatiion of lung cancer cells. Based on our results magntic PLGA/ PEG loaded with Met and Sil was able to kill lung cancer cells more rapidly than other groups, thus potentially this strategy can decrease side effects and cytotoxicity. Furthermore, according to our outcomes nano-formulation of Met and Sil with magntic PLGA/PEG can suppress leptin gene expression and its recepror of human lung cancerous A549 cells more that free form, therefore nano-coencapsulated state of Met and Sil has significant potential to use as complement drug for treatment of lung cancer. These results imply that loading of Met and Sil in magntic PLGA/PEG NPs as we have displayed here could result in hopeful candidates for treatment of lung cancer with a specific final goal of reducing drug resistance related to the current clinically used therapeutics.

\section{Author Contribution Statement}

SE and LF as the main colleague contributed to performing experiments, data analysis, and manuscript writing; JD and $\mathrm{MH}$ as main colleagues were involved in manuscript writing; DM and $\mathrm{ZN}$ as the executive of the project was involved in conception and design, manuscript writing, and supervised the manuscript preparation.

\section{Acknowledgments}

Also, authors would like to thank the Stem Cell Research Center for the use of their laboratory facilities..

\section{Funding}

This study was financially supported by grant No: 995537 of the National Institute for Medical Research Development

\section{Conflict of Interest}

The authors declare that they have no competing interests.

\section{References}

Abbasi A, Dadashpour M, Alipourfard I (2021). Calculation of radium-223 and actinium-225 $\alpha$-emitter radiopharmaceuticals dose rates in treatment of metastatic castration-resistant prostate cancer. $J$ Cancer Res Ther, 17, 348.

Abotaleb M, Kubatka P, Caprnda M, et al (2018). Chemotherapeutic agents for the treatment of metastatic breast cancer: An update. Biomed Pharm, 101, 458-77.

Adlravan E, Nejati K, Karimi MA, et al (2021). Potential activity of free and PLGA/PEG nanoencapsulated nasturtium officinale extract in inducing cytotoxicity and apoptosis in human lung carcinoma A549 cells. J Drug Deliv Sci Technol, 61, 102256.

Ahima RS, Flier JS (2000). Leptin. Ann Rev Physiol, 62, 413-37. Akbari E, Mousazadeh H, Sabet Z, et al (2021). Dual drug delivery of trapoxin $A$ and methotrexate from biocompatible PLGA-PEG polymeric nanoparticles enhanced antitumor 
activity in breast cancer cell line. J Drug Deliv Sci Technol, 61, 102294.

Amirsaadat S, Jafari-Gharabaghlou D, Alijani S, et al (2021). Metformin and Silibinin co-loaded PLGA-PEG nanoparticles for effective combination therapy against human breast cancer cells. J Drug Deliv Sci Technol, 61, 102107.

Artac M, Altundag K (2012). Leptin and breast cancer: an overview. Med Oncol, 29, 1510-4.

Bain G, Collie-Duguid E, Murray GI, et al (2014). Tumour expression of leptin is associated with chemotherapy resistance and therapy-independent prognosis in gastrooesophageal adenocarcinomas. Br J Cancer, 110, 1525-34.

Chatran M, Pilehvar-Soltanahmadi Y, Dadashpour M, et al (2018). Synergistic anti-proliferative effects of metformin and silibinin combination on T47D breast cancer cells via hTERT and cyclin D1 inhibition. Drug Res, 68, 710-6.

Cukierman E, Khan DR (2010). The benefits and challenges associated with the use of drug delivery systems in cancer therapy. Biochem Pharmacol, 80, 762-70.

D'Marco L, Puchades MJ, Gorriz JL, et al (2020). Epicardial adipose tissue, adiponectin and leptin: a potential source of cardiovascular risk in chronic kidney disease. Int $\mathrm{J} \mathrm{Mol}$ Sci, 21, 978.

Dai W, Wang X, Song G, et al (2017). Combination antitumor therapy with targeted dual-nanomedicines. Adv Drug Deliv Rev, 115, 23-45.

Deatsch AE, Evans BA (2014). Heating efficiency in magnetic nanoparticle hyperthermia. J Magn Magn Mater, 354, 163-72.

Dutta D, Ghosh S, Pandit K, et al (2012). Leptin and cancer: Pathogenesis and modulation. Indian J Endocrinol Metab, 16, S596.

Farajzadeh R, Pilehvar-Soltanahmadi Y, Dadashpour M, et al (2018). Nano-encapsulated metformin-curcumin in PLGA/ PEG inhibits synergistically growth and hTERT gene expression in human breast cancer cells. ArtifCells Nanomed Biotechnol, 46, 917-25.

Faramarzi L, Dadashpour M, Sadeghzadeh H, et al (2019). Enhanced anti-proliferative and pro-apoptotic effects of metformin encapsulated PLGA-PEG nanoparticles on SKOV3 human ovarian carcinoma cells. Artif Cells Nanomed Biotechnol, 47, 737-46.

Firouzi-Amandi A, Dadashpour M, Nouri M, et al (2018). Chrysin-nanoencapsulated PLGA-PEG for macrophage repolarization: Possible application in tissue regeneration. Biomed Pharmacother, 105, 773-80.

Hashemi B, Firouzi-amandi A, Amirazad H, et al (2021). Emerging importance of nanotechnology-based approaches to control the COVID-19 pandemic; focus on nanomedicine iterance in diagnosis and treatment of COVID-19 patients. J Drug Deliv Sci Technol, 2021, 102967.

Jafari-Gharabaghlou D, Pilehvar-Soltanahmadi Y, Dadashpour $\mathrm{M}$, et al (2018). Combination of metformin and phenformin synergistically inhibits proliferation and hTERT expression in human breast cancer cells. Iran J Basic Med Sci, 21, 1167.

Javan N, Khadem Ansari MH, Dadashpour M, et al (2019). Synergistic antiproliferative effects of co-nanoencapsulated curcumin and chrysin on mda-mb-231 breast cancer cells through upregulating mir-132 and mir-502c. Nutr Cancer, 71, 1201-13.

Jeddi F, Alipour S, Najafzadeh N, et al (2019). Reduced levels of miR-28 and miR-200a act as predictor biomarkers of aggressive clinicopathological characteristics in gastric cancer patients. Galen Med J, 8, e1329.

Johannsen M, Thiesen B, Wust P, et al (2010). Magnetic nanoparticle hyperthermia for prostate cancer. Int J Hyperth, 26, 790-5.
Kobayashi T (2011). Cancer hyperthermia using magnetic nanoparticles. Biotechnol J, 6, 1342-7.

Latorre M, Rinaldi C (2009). Applications of magnetic nanoparticles in medicine: magnetic fluid hyperthermia. Puerto Rico Health Sci J, 28.

Maasomi ZJ, Soltanahmadi YP, Dadashpour M, et al (2017). Synergistic anticancer effects of silibinin and chrysin in T47D breast cancer cells. Asian Pac J Cancer Prev, 18, 1283.

Mellatyar H, Talaei S, Pilehvar-Soltanahmadi Y, et al (2018). 17-DMAG-loaded nanofibrous scaffold for effective growth inhibition of lung cancer cells through targeting HSP90 gene expression. Biomed Pharm, 105, 1026-32.

Mogheri F, Jokar E, Afshin R, et al (2021). Co-delivery of metformin and silibinin in dual-drug loaded nanoparticles synergistically improves chemotherapy in human non-small cell lung cancer A549 cells. J Drug Deliv Sci Technol, 66, 102752 .

Mohandesnezhad S, Pilehvar-Soltanahmadi Y, Alizadeh E, et al (2020). In vitro evaluation of Zeolite-nHA blended PCL/ PLA nanofibers for dental tissue engineering. Mater Chem Phys, 252, 123152.

Mollazade M, Zarghami N, Nasiri M, et al (2011). Polyamidoamine (PAMAM) encapsulated curcumin inhibits telomerase activity in breast cancer cell line. Clin Biochem, 13, S217.

Moorthi C, Kathiresan K (2013). Fabrication of highly stable sonication assisted curcumin nanocrystals by nanoprecipitation method. Drug Invent Today, 5, 66-9.

Mousazadeh H, Pilehvar-Soltanahmadi Y, Dadashpour M, et al (2021). Cyclodextrin based natural nanostructured carbohydrate polymers as effective non-viral siRNA delivery systems for cancer gene therapy. $J$ Control Release, 330, 1046-70.

Nagaraj NS, Datta PK (2010). Targeting the transforming growth factor- $\beta$ signaling pathway in human cancer. Expert Opin Investig Drugs, 19, 77-91.

Nejati-Koshki K, Akbarzadeh A, Pourhassan-Moghaddam M (2014). Curcumin inhibits leptin gene expression and secretion in breast cancer cells by estrogen receptors. Cancer Cell Int, 14, 66.

Nejati K, Dadashpour M, Gharibi T, et al (2021). Biomedical applications of functionalized gold nanoparticles: A Review. J Clust Sci, 2021, 1-16.

Nikmanesh F, Sarhadi S, Dadashpour M, et al (2020). Omics integration analysis unravel the landscape of driving mechanisms of colorectal cancer. Asian Pac J Cancer Prev, 21, 3539.

Pourgholi A, Dadashpour M, Mousapour A, et al (2021). Anticancer potential of silibinin loaded polymeric nanoparticles against breast cancer cells: Insight into the Apoptotic Genes Targets. Asian Pac J Cancer Prev, 22, 2587-96.

Rasouli S, Montazeri M, Mashayekhi S, et al (2020). Synergistic anticancer effects of electrospun nanofiber-mediated codelivery of Curcumin and Chrysin: Possible application in prevention of breast cancer local recurrence. J Drug Deliv Sci Technol, 55, 101402.

Salloum M, Ma R, Weeks D, et al (2008). Controlling nanoparticle delivery in magnetic nanoparticle hyperthermia for cancer treatment: experimental study in agarose gel. Int J Hyperther, 24, 337-45.

Samadzadeh S, Mousazadeh H, Ghareghomi S, et al (2021). In vitro anticancer efficacy of Metformin-loaded PLGA nanofibers towards the post-surgical therapy of lung cancer. J Drug Deliv Sci Technol, 61, 102318.

Serati-Nouri H, Rasoulpoor S, Pourpirali R, et al (2021). In vitro expansion of human adipose-derived stem cells with delayed senescence through dual stage release of curcumin from 
mesoporous silica nanoparticles/electrospun nanofibers. Life Sci, 285, 119947.

Sheervalilou R, Ansarin K, Fekri Aval S, et al (2016). An update on sputum Micro RNA s in lung cancer diagnosis. Diagn Cytopathol, 44, 442-9.

Shen Y, Wang Q, Zhao Q, et al (2009). Leptin promotes the immune escape of lung cancer by inducing proinflammatory cytokines and resistance to apoptosis. Mol Med Rep, 2, 295-9.

Singh RP, Agarwal R (2004). A cancer chemopreventive agent silibinin, targets mitogenic and survival signaling in prostate cancer. Mutat Res Fundam Mol Mech Mutagen, 555, 21-32.

Singh RP, Agarwal R (2006). Prostate cancer chemoprevention by silibinin: bench to bedside. Molecular Carcinogenesis: Published in cooperation with the University of Texas MD Anderson Cancer Center, 45, 436-42.

Sivakumar B, Aswathy RG, Sreejith R, et al (2014). Bacterial exopolysaccharide based magnetic nanoparticles: a versatile nanotool for cancer cell imaging, targeted drug delivery and synergistic effect of drug and hyperthermia mediated cancer therapy. J Biomed Nanotechnol, 10, 885-99.

Thiesen B, Jordan A (2008). Clinical applications of magnetic nanoparticles for hyperthermia. Int J Hyperther, 24, 467-74.

Tsuchiya T, Shimizu H, Horie T, et al (1999). Expression of leptin receptor in lung: leptin as a growth factor. Eur $J$ Pharmacol, 365, 273-9.

Xu M, Cao F-L, Li N, et al (2018). Leptin induces epithelial-tomesenchymal transition via activation of the ERK signaling pathway in lung cancer cells. Oncol Lett, 16, 4782-8.

Yang J, Park S-B, Yoon H-G, et al (2006). Preparation of poly $\varepsilon$-caprolactone nanoparticles containing magnetite for magnetic drug carrier. Int J Pharm, 324, 185-90.

Zakikhani M, Dowling R, Fantus IG, et al (2006). Metformin is an AMP kinase-dependent growth inhibitor for breast cancer cells. Cancer Res, 66, 10269-73.

\section{(c) (1) () ()}

This work is licensed under a Creative Commons AttributionNon Commercial 4.0 International License. 